\title{
Stress and relapse of breast cancer
}

\author{
Amanda J Ramirez, Thomas K J Craig, James P Watson, Ian S Fentiman, William R S North, \\ Robert D Rubens
}

\begin{abstract}
To elucidate the association between stressful life events and the development of cancer the influence of life stress on relapse in operable breast cancer was examined in matched pairs of women in a casecontrol study. Adverse life events and difficulties occurring during the postoperative disease free interval were recorded in 50 women who had developed their first recurrence of operable breast cancer and during equivalent follow up times in $\mathbf{5 0}$ women with operable breast cancer in remission. The cases and controls were matched for the main physical and pathological factors known to be prognostic in breast cancer and sociodemographic variables that influence the frequency of life events and difficulties. Severely threatening life events and difficulties were significantly associated with the first recurrence of breast cancer. The relative risk of relapse associated with severe life events was 5.67 ( $95 \%$ confidence interval 1.57 to $37 \cdot 20$ ), and the relative risk associated with severe difficulties was 4.75 (1.58 to 19.20). Life events and difficulties not rated as severe were not related to relapse. Experiencing a non-severe life event was associated with a relative risk of $2.0(0.62$ to 7.47$)$, and experiencing a non-severe difficulty was associated with a relative risk of $1.13(0.38$ to 3.35$)$.
\end{abstract}

These results suggest a prognostic association between severe life stressors and recurrence of breast cancer, but a larger prospective study is needed for confirmation.

\section{Introduction}

The association between stressful life events and the development of cancer is supported by a large body of anecdotal clinical evidence that has been collected since the eighteenth century. Recent, more substantive clinical and epidemiological evidence for a link between life events and the onset of cancer has been less consistent and flawed by conceptual and methodological weaknesses. ' The most important of these shortcomings has been the inability to date accurately the onset of tumour growth. This is a necessary prerequisite for any study claiming to investigate the influence of stress on that onset. Moreover, unreliable measures of stressful experiences have been used and control groups have been poorly chosen.

The role of life events in the prognosis of cancer has received much less attention but is more easily studied because progression of the disease is more amenable to measurement. Early and accurate diagnosis of relapse is facilitated by the regular follow up of patients with cancer in oncology units. Using a measure of life events that overcomes many of the problems of low reliability and validity that have undermined research on life stress, ${ }^{3}$ we examined the influence of adverse life experiences on the development of relapse in women with operable breast cancer.

\section{Patients and methods}

Data on life events were collected from 50 consecutive women who had developed a first recurrence after treatment of operable breast cancer. Recurrences (local or distant) were diagnosed according to the criteria of Hayward et al. ${ }^{4}$ Similar data were obtained from a control group of women whose operable breast cancer was in remission according to clinical and investigatory criteria.

The matching of the women who had a relapse with their controls was performed by computer searches of the database at the clinical oncology unit, Guy's Hospital, which contains clinical, pathological, and demographic information on all women with breast cancer who have attended the unit. The cases and controls were matched in pairs for the main physical and pathological factors known to be prognostic in breast cancer. These included type of operation, whether or not the patient had received adjuvant chemotherapy, menopausal state, affected lymph nodes, tumour size, and histological type of tumour. The cases and controls were then also matched for date of operation and those sociodemographic variables that influence the frequency of life events in the general population.

For the women whose breast cancer relapsed the life events data were collected for the period between the date of operation and the date of recurrence. The life events data for the controls were ascertained over the equivalent follow up period from the date of their operation. Adverse life experiences were measured with the Bedford College life events and difficulties schedule, ${ }^{2}$ an instrument based on an interview that assesses not only discrete life events but also more persistent, continuing difficulties. Only those adverse life events and difficulties (stressors) that met strictly predefined criteria were considered for inclusion. The severity of stressors was rated by a panel of judges according to their undesirability and threat to the subject. Ratings were based on how a hypothetical woman would be expected to react, given the details of the events, the circumstances surrounding them, and the woman's biography. The raters were kept ignorant of the subject's emotional reaction to the event. This approach reduced any bias stemming from the subject, whose recall and report of events may have been influenced by an attempt to make sense of her disease. Because the ratings were made by a panel of independent judges the potential bias stemming from the investigator was brought under control. Raters did not know whether the event was followed by a recurrence of disease, thus avoiding the influence of any judgments about likely causal links between events and relapse of the disease.

Life events were rated as severe if they had threatening implications in the long term and consequences that were either pronounced or moderate and focused on the woman herself or jointly with someone else, such as the death of a husband or child, divorce, or arguments leading to a complete breakdown of important family relationships. Difficulties that carried a pronounced threat and persisted for at least six months were similarly rated as severe-for example, the problem for a 52 year old woman of caring for her 22 year old son, severely physically handicapped with cerebral palsy, as she provided 24 hour
Correspondence to: Dr Ramire\%. 
total care for him. Life events and difficulties rated as not severe were those that carried only little or no long term threat: events such as the only son of a happily married woman leaving home to join the army and being expected to do tours in Northern Ireland, and difficulties such as the husband who drinks three to four pints of beer a night and spends most of the extra family money on alcohol, who may be quarrelsome but is never violent and has always been in employment.

The relative risk of relapse associated with life events and difficulties was calculated as the Mantel-Haenszel odds ratio, and $95 \%$ confidence intervals were derived by the exact method. Values for $\chi^{2}$ and $\mathrm{p}$ were derived from McNemar's test with continuity correction for the pair matched case-control data. ${ }^{5}$ These analyses were based on pairs of women who were discordant for the experience of a stressor-namely, those pairs in which one member had a stressor and the other did not. The concordant pairs, in which both or neither experienced a stressor, did not contribute any evidence for causality and so were ignored in the analyses.

\section{Results}

All the women who were asked to participate in the study agreed to be interviewed. The average age of the women was 49.5 (SD 9.2) years. Altogether 83 were married, three were single, four were divorced, and 10 were widowed. The median interval free of disease for the women who had a relapse of breast cancer was 30.5 months (range 9-145).

TABLE I-Matching of 50 women who had a relapse of breast cancer (cases) and 50 women who did not (controls) for physical and pathological factors

\begin{tabular}{lrr}
\hline & $\begin{array}{c}\text { No of } \\
\text { cases }\end{array}$ & $\begin{array}{c}\text { No of } \\
\text { controls }\end{array}$ \\
\hline Primary operation: & & \\
Mastectomy & 36 & 36 \\
Conservation procedure & 14 & 14 \\
Adjuvant chemotherapy: & 38 & 38 \\
None & 3 & 3 \\
Melphalan & 9 & 9 \\
Cyclophosphamide, methotrexate, fluorouracil & & \\
Menopausal state: & 29 & 28 \\
Premenopausal & 6 & 6 \\
Perimenopausal & 15 & 16 \\
Postmenopausal & 19 & 19 \\
No of axillary lymph nodes affected: & 19 & 17 \\
0 & 11 & 13 \\
1-3 & 1 & 1 \\
4-15 & & \\
>15 & 2 & 2 \\
Histological type of tumour: & 23 & 23 \\
Ductal grade I & 19 & 20 \\
Ductal grade II & 5 & 4 \\
Ductal grade III & 1 & 0 \\
Lobular & 12 & 10 \\
Medullary & 32 & 37 \\
Tumour size: & 6 & 3 \\
$T_{1}$ & & \\
$T_{2}$ & \\
$T_{3}$ & & \\
\hline
\end{tabular}

The pairs were well matched for the treatments they received, with only minor mismatches for menopausal state, number of affected axillary lymph nodes, tumour size, and histological type of tumour. There were no major mismatches for age, marital state, social class, and life stage (an index reflecting age and the presence of children in the subject's household). Table I gives an overall comparison of the prognostic factors in the cases and controls.

Table II shows the numbers of pairs of women who experienced at least one adverse stressor during the disease free interval or the equivalent follow up time. In 10 pairs only the woman who had a relapse had experienced any adverse life event and in four pairs only the control had. Hence the relative risk for relapse associated with an adverse life event of any severity was $2 \cdot 5(p=0 \cdot 2)$. Experience of non-severe life events was associated with a lower relative risk of $2 \cdot 00(p=0 \cdot 3)$. In 17 pairs the woman who had a relapse had experienced a severe life event and her control had not, and in three pairs the control had experienced a severe life event and the woman who had a relapse had not. Thus, a significant relative risk $(5 \cdot 67)$ was associated with the experience of a severe life event $(p=0 \cdot 004)$.

The relative risk of relapse associated with the experience of difficulties followed a similar pattern. For difficulties of any severity the relative risk was $2 \cdot 80$ $(\mathrm{p}=0 \cdot 7)$ and for non-severe difficulties $1 \cdot 13(\mathrm{p}=1 \cdot 0)$, whereas experience of severe difficulties was associated with a significant relative risk of $4.75(p=0.004)$. Experiencing either a severe life event or a severe difficulty was associated with an even greater relative risk (9.00): there were nine times as many pairs in which only the woman who had a relapse had experienced a severe stressor of either type as there were pairs in which only the control had $(\mathrm{p}<0.001)$.

\section{Discussion}

The findings of this study suggest a prognostic association between severe life stressors and recurrence of operable breast cancer. Whether overall survival from breast cancer is altered by severe stress has yet to be determined. Results of recent studies using cancer mortality statistics provide some support for the link between adverse life events and survival with cancer. Based on data from the Office of Population Censuses and Surveys a weak association was found between death of a wife and subsequent death from cancer of the widower after a long latent interval, ${ }^{7}$ but further follow up of the cohort of widowers is required before final conclusions can be drawn. Also, decreased survival with breast cancer was shown in women aged over 60 who had experienced death, illness, or unemployment in members of their household in the five years before their malignant disease was diagnosed. ${ }^{8}$

The design of our study overcame many of the

TABLE II - Relation between life stressors and relapse in 50 pairs of women with breast cancer

\begin{tabular}{|c|c|c|c|c|c|c|c|}
\hline \multirow[b]{2}{*}{ Type of stressor } & \multicolumn{2}{|c|}{ No of concordant pairs } & \multicolumn{2}{|c|}{ No of discordant pairs } & \multirow{2}{*}{$\begin{array}{c}\begin{array}{c}\text { Relative risk of } \\
\text { relapse associated } \\
\text { with experience of } \\
\text { stressor }\end{array} \\
\\
\begin{array}{c}\text { Odds ratio* }(95 \% \\
\text { confidence interval })\end{array}\end{array}$} & \multirow[b]{2}{*}{$x^{2} \dagger$} & \multirow[b]{2}{*}{$\mathrm{p} \dagger$} \\
\hline & $\begin{array}{c}\text { Both patients } \\
\text { experienced stressor }\end{array}$ & $\begin{array}{c}\text { Neither patient } \\
\text { experienced stressor }\end{array}$ & $\begin{array}{l}\text { Only patient who } \\
\text { relapsed experienced } \\
\text { stressor }\end{array}$ & $\begin{array}{c}\text { Only control } \\
\text { experienced stressor }\end{array}$ & & & \\
\hline Any event & 34 & 2 & 10 & 4 & $2.50(0.72$ to 10.93$)$ & 1.79 & $0 \cdot 181$ \\
\hline Non-severe event & 31 & 4 & 10 & 5 & $2.00(0.62$ to 7.47$)$ & 1.07 & $0 \cdot 303$ \\
\hline Severe event & 9 & 21 & 17 & 3 & $5.67(1.57$ to 37.20$)$ & $8 \cdot 45$ & 0.004 \\
\hline Any difficulty & 21 & 10 & 14 & 5 & $2.80(0.95$ to 9.93$)$ & $3 \cdot 37$ & 0.066 \\
\hline Non-severe difficulty & 14 & 19 & 9 & 8 & $1 \cdot 13(0.38$ to $3 \cdot 35)$ & 0.00 & 1.000 \\
\hline Severe difficulty & 6 & 21 & 19 & 4 & $4.75(1.58$ to 19.20$)$ & $8 \cdot 52$ & 0.004 \\
\hline Any severe stressors $\ddagger$ & 13 & 17 & 18 & 2 & $9.00(2.15$ to 79.97$)$ & $11 \cdot 25$ & $<0.001$ \\
\hline
\end{tabular}

Mantel-Haenszel test.

+McNemar's test.

$\ddagger$ Either a severe life event or a severe difficulty. 
objections to the previous research that looked at stress and the development of cancer. In particular, we rigorously controlled for the main physical and pathological factors that are known to influence prognosis in breast cancer. A measure of life stressors was used that accurately dated events and difficulties to ensure that they preceded the clinical onset of progression of the disease. This measure also attempted to assess the objective threat of life events and difficulties independently of both the subject's emotional reaction and investigator bias. This is important as neither the patient nor the investigator could be blinded to the woman's disease state. Unconsciously motivated differences in the subject's recall and interviewer's techniques remain a possible source of bias. If these were operating, however, a more systematic excess of both non-severe and severe stressors among the women with a relapse would be expected.

The small numbers of women who participated in this study must be borne in mind when interpreting the results, a factor that is reflected in the wide confidence intervals associated with the estimates of relative risk. The findings of this study now need to be corroborated in a large prospective investigation.

The mechanism whereby stress might affect the relapse of breast cancer is unknown. Suggested intermediaries include the neuroendocrine ${ }^{y}$ and immune systems, ${ }^{1011}$ which could promote growth of previously dormant or subclinical metastases. Investigations of this are complex and difficult. ${ }^{12-14}$ Modifications in behaviour leading to direct exposure to carcinogens must also be considered as a possible mediating process.

The impact of severe life stressors on the recurrence of breast cancer may be modified by other psychosocial factors. Further analysis is required to explore the interaction between severe life stressors and variables such as coping behaviour and social support, both of which have been suggested as prognostic factors in themselves. ${ }^{15-17}$ Understanding the nature of such interactions may have important implications for managing patients and for the development of cognitive $^{1819}$ and other psychological treatments aimed at helping patients with cancer adjust to the impact of their disease and cope with the consequences of subsequent severe life stressors.

1 Ramirez AJ. Life events and cancer: conceptual and methodological issues. In: Watson .11, Greer S, Thomas C, eds. Psychosocial oncology. Oxford: Pergamon, 1988:53-60

2 Craig TKJ, Brown GW. Life events: meaning and physical illness. In: Steptoe A, Mathews A, eds. Health care and human behaviour. New York: Academic Press, 1984:7-39.

3 Brown GW, Harris T. Social origins of depression. Cambridge: Cambridge University Press, 1978

+ Hayward JL, Meakin JM, Stewart HJ. Assessment of response and recurrence in breast cancer. Sem Oncol 1978:4:445-9.

5 Breslow NE, Day NE. Statistical methods in cancer research. Vol 1. The analysis of case control studies. Lyons: International Agency for Research on Cancer, 1980.

6 Ashraf J, Fentiman IS. Conservative treatment of early breast cancer. Br J Hosp Med 1986;35:263-5.

7 Jones DR, Goldblatt PO, Leon DA. Bereavement and cancer: some data on deaths of spouses from the longitudinal study of Office of Population Censuses and Surveys. Br.Med f 1984;289:461-4.

8 Funch DP, Marshall J. The role of stress, social support and age and survival from breast cancer. $\mathcal{F}$ Psychosom Res 1983;27:77-83.

$9 \mathrm{Katz}$ J, Gallagher TS. Psychoendocrine considerations in cancer of the breast. Ann NY Acad Sci 1969;164:509-16.

10 Kiecolt-Glaser JN, Garner W, Speicher C, Penn GM, Holloway BS. Psychosocial modifiers of immunocompetence in medical students. $\mathcal{F}$ Psychosom Med 1984;46:7-14.

11 Bartrop RW, Lazarus L, Luckhurst E, Kiloh LG, Penny R. Depressed lymphocyte function after bereavement. Lancet 1977;i:834-6.

12 Fox BH. Psychosocial factors in the immune system in human cancer. In: Ader R, ed. Psychormmunology. New York: Academic Press, 1981:103-58.

13 Cox T, Mackay C. Psychosocial factors and psychophysiological mechanisms in the aetiology and development of cancer. Soc Sci Med 1982;16:381-96.

14 Pettingale KW. Towards a psychobiological model of cancer: biological considerations. Soc Sci Med 1985;20:179-87.

15 Pettingale KW Morris T, Greer S, Haybrittle JI Mental atritudes to cancer: an additional prognostic factor. Lancet $1981 ; i: 750$.

16 Temoshok L. Biopsychological studies in cutaneous malignant melanoma. Soc Sci Med 1985;20:833-40.

17 Goodwin JS, Williams WC, Key CR, Sarnet JM. The effect of marital status on stage, treatment and survival of cancer patients. $\mathcal{F} A M A$ 1987;258:3125-30. 18 Greer S, Moorey S. Adjuvant psychological therapy for cancer patients. Eur $\mathcal{f}$ Surg Oncol 1987;13:511-16.

19 Tarrier N, Maguire P, Kincey J. Locus of control and cognitive behaviour therapy with mastectomy patients. Br F Med Psychol 1983;56:265-70.

Accepled 17 Nowember 1988
Wessex Regional Health Authority, Winchester SO22 5DH

Ruth M Shakespeare, MRCP, senior registrar in community medicine

Martin C Woolaway, MFCM, director of community medicine

Correspondence to: Dr Ruth M Shakespeare,

Western Hospital,

Southampton SO9 4NQ.

BrMed f 1989;298:293-4

\section{Smoking in hospitals: a measure of improvement}

\section{Ruth M Shakespeare, Martin C Woolaway}

The argument for restrictions on smoking in health service premises is clear. Most smokers and nonsmokers support restrictions in hospitals, ${ }^{\prime}$ and the Department of Health and Social Security set out firmly the exemplary role that health authorities should have in the campaign to stop smoking.

A survey of all health service premises in the Wessex region was undertaken in 1981, and the information obtained was used to set goals for reducing smoking in hospitals and health centres by $1985 .{ }^{34}$ We carried out a study in 1985 to monitor the progress towards these goals and to identify improvements that might be made.

\section{Methods and results}

We asked administrators of all health service premises in Wessex to complete a postal questionnaire identical with that used in the survey in $1981 .{ }^{3}$ We requested information on the extent of restrictions on smoking in their premises; how restrictions on smoking were identified and monitored; and sales of cigarettes. We inspected a sample of the premises to validate the results. Replies were received from 246 of the 250 premises.

\section{RESTRICTIONS ON SMOKING IN PUBLIC AREAS}

Short stay hospitals $(\mathrm{n}=61)$ - The proportion of hospitals achieving the recommended goals in wards and outpatient and other public areas had increased since 1981 (table). Only 23 of the hospitals, however, had achieved the desired goal for day rooms. Fifty three offered day rooms where smoking was permitted, while only 26 provided day rooms that were always smoke free.

Maternity hospitals $(\mathrm{n}=7)$ - The high level of restrictions found in 1981 was maintained, with no smoking in any of the wards. Restrictions in day rooms were less satisfactory.

Psychiatric hospitals $(\mathrm{n}=32)$ - Low levels of restrictions were found in all areas.

Long stay and geriatric hospitals $(\mathrm{n}=45)$ - The proportion of premises with satisfactory restrictions had increased since 1981.

Health centres $(n=44)$-Forty two of the health centres had a total ban on smoking in public areas.

The task of monitoring restrictions was undertaken by nurses and administrators, while doctors had a minor role.

\section{RESTRICTIONS ON SMOKING IN STAFF AREAS}

Canteen and restaurant facilities-Restrictions had increased since 1981, but one third of long stay and 